\title{
Senior oversight of rapid TTO and information exchange (SORTIE) discharge letter: a pilot evaluation
}

\author{
Authors: David Eveson, ${ }^{\mathrm{A}}$ Chris Miller, ${ }^{\mathrm{A}}$ Amin Amin, ${ }^{\mathrm{A}}$ Mark Taylor ${ }^{\mathrm{A}}$ and Abigail Lawrence ${ }^{\mathrm{A}}$
}

\section{Introduction}

Organising timely hospital discharge can be a challenge. In this hospital trust, a perceived barrier is delay in generating a TTO ('to take out' or discharge summary) letter. There are further steps dependent on this correspondence that must be undertaken before leaving hospital, including pharmacy check of discharge medication, dispensary, arranging transport, nurse sign-off and additional correspondence (eg anticoagulant handover). Projects to facilitate opportune TTO writing have met with limited success: principal barriers being precedence of clinical work, continuity of care at junior doctor level and unwieldy templates (a standard stroke discharge template comprises over 30 mandatory fields). A group of consultant physicians wished to evaluate an abbreviated TTO template, SORTIE (senior oversight of rapid TTO and information exchange) which was to be co-authored by the consultant at the point hospital discharge was indicated on clinical grounds. It would consist of a set of minimum required headings, allowing for a narrative summary to be written comprising information deemed to be necessary for the effective handover of care.

\section{Materials and methods}

We did a prospective before (Phase 1: 05 August 2019 to 13 September 2019) versus after (Phase 2: 18 September to 11 October 2019) study of the use of the SORTIE template on two acute medical wards (stroke medicine and geriatric medicine) involving three consultants. On the stroke medicine ward, SORTIE letters were written immediately after the morning board round for patients who could leave hospital that day, and on the geriatrics ward, junior doctors commenced the letter on admission and it was finalised by the consultant. Process data (to include time of discharge and length of stay) were compiled from hospital audit systems. Qualitative feedback from care providers, service users and carers/relatives was sought by listing the consultant mobile phone number on the template with an explanation that this was a pilot evaluation. The effect on pharmacy services and medical coding was included.

\section{Results and discussion}

Quantitative data from the study are shown in Table 1.

\begin{tabular}{|c|c|c|}
\hline Metric & $\begin{array}{l}\text { Phase } 1 \\
\text { (Standard TTO) }\end{array}$ & $\begin{array}{l}\text { Phase } 2 \\
\text { (SORTIE TTO) }\end{array}$ \\
\hline Discharges & 96 & 53 \\
\hline $\begin{array}{l}\text { Median time to write } \\
\text { TTO }\end{array}$ & 33 mins & 18 mins \\
\hline $\begin{array}{l}\text { Median time of day TTO } \\
\text { submitted to pharmacy }\end{array}$ & $14: 21$ & $11: 07$ \\
\hline $\begin{array}{l}\% \text { of TTOs submitted } \\
\text { to pharmacy before } \\
\text { midday }\end{array}$ & $29 \%$ & $57 \%$ \\
\hline $\begin{array}{l}\text { Time of leaving hospital } \\
\text { (same day) }\end{array}$ & $18: 12$ & $16: 07$ \\
\hline Median length of stay & 6.6 days & 6.4 days \\
\hline
\end{tabular}

Regarding qualitative data, junior doctors reported being more enthusiastic and engaged in writing TTOs and appreciated the freer-form nature of the template. One phone call was received from a relative praising its user-friendly nature. One care provider commented how poor quality the TTO was in Phase 1. Having a pharmacist present when the consultant generated the discharge medication list appeared to reduce the chance of prescribing errors.

\section{Conclusion}

This pilot evaluation appeared to demonstrate a beneficial effect of an abbreviated, consultant-led TTO document on timelier hospital discharge and was generally accepted by hospital staff and service users. A full statistical analysis is to be carried out and we plan a broader and lengthier evaluation.

\section{Conflicts of interest}

None declared. 